\title{
EFFECT OF RESIDUAL LIGNIN AND HEXENURONIC ACIDS ON THE GENERATION OF ORGANOCHLORINES WITH CHLORINE DIOXIDE
}

\author{
TÂNIA CRISTINA FRIGIERI," GUSTAVO VENTORIM** and \\ ANA PAULA ALMEIDA FERRAZ ${ }^{* * *}$ \\ "Demétrio Azevedo Júnior State Technical School, Itapeva, Brazil \\ ${ }^{* *}$ São Paulo State University (UNESP), Department of Wood Industrial Engineering, Itapeva, Brazil \\ ${ }^{* * * *}$ São Paulo State University (UNESP), School of Engineering, Department of Mechanical Engineering, \\ Guaratingueta Campus, Brazil \\ $\bowtie$ Corresponding author: Gustavo Ventorim,ventorim@itapeva.unesp.br
}

Received April 18, 2018

\begin{abstract}
The pulp and paper industry is one of the leading economic sectors that contribute to the contamination of the environment because of the use of organochlorine compounds, especially during the pulp bleaching process. For this reason, the objective of the present work was to analyze the organochlorines generated in the bleaching effluent (adsorbable organic halides, AOX). For this study, chips of Eucalyptus urograndis were subjected to the kraft cooking process. The thus-obtained brown pulp was divided into three samples: one remained unmodified, another was subjected to a treatment for removing lignin (TLR) and the third was treated to remove hexenuronic acids (THR). A pre-bleaching sequence (DE) was performed on the three pulp samples (brown, TLR and THR), for different kappa factors in order to determine the amount of AOX generated in the effluent. The results indicated that the lignin, when compared to the hexenuronic acids, generated a higher amount of AOX in the effluent.
\end{abstract}

Keywords: lignin, hexenuronic acids, AOX

\section{INTRODUCTION}

Growing global awareness of water scarcity has led to introducing a new perspective on environmental matters, which would govern the legal, political, economic and administrative scenarios of many industrial processes.

The basic criteria for assessing the environmental management in the pulp and paper industry are the sustainable use of forests, the amount of fresh water captured, the content of recycled fibers, the use of chlorine and chlorine dioxide in the bleaching process, the chemical and biological emission standards, and the final impact of the organochlorine compounds (adsorbable organic halides, AOX) in the effluent. The AOX, according to Corazza, ${ }^{1}$ are the organochlorine compounds present in the effluents of cellulose industries that use elemental chlorine and/or chlorine-based compounds during the bleaching stage.

Mounteer ${ }^{2}$ defines AOX as the measurement of the amount of chlorine related to organic compounds. This method has been developed to assess the environmental impact of the bleaching sequence effluents that incorporate chlorine-based reagents.

AOX result from the reaction between the residual lignin of wood fibers and the chlorinebased compounds used in pulp bleaching. ${ }^{3}$ According to Suess, Leporini and Schmidt, ${ }^{4}$ the AOX are also heavily dependent on the amount of hexenuronic acid existing in the pulp.

The AOX present in the effluent can cause enormous health risks because of their carcinogenicity, mutagenicity and acute and chronic toxicity to various aquatic organisms. ${ }^{3}$ In addition, Ruas ${ }^{5}$ states that the disposal of effluents containing refractory compounds has become a matter of concern and research has been focused on improving the quality of effluents without impacting the quality of the final pulp.

Colodette and Santos ${ }^{6}$ have reported an increasing tendency to shorten the bleaching 


\section{TÂNIA CRISTINA FRIGIERI et al.}

procedure, for example, currently, for oxygen predelignified eucalyptus kraft pulp, only three stages of bleaching are sufficient.

In order to analyze the formation of AOX in the effluent, in the present study, three cellulose pulps were obtained by the kraft cooking process, with different amounts of lignin and hexenuronic acids, and their effects on the AOX generated in the effluent after a sequence of the chlorine dioxide (D) and alkaline extraction (E) stages were investigated.

\section{EXPERIMENTAL}

\section{Materials}

For this study, chips of 7-year-old Eucalyptus urograndis, from the city of Capão Bonito in the state of São Paulo, Brazil, were used.

\section{Pulping}

The operating conditions are presented in Table 1. After cooking, the brown pulp was removed from the capsules and washed with water at room temperature, using a $0.06-\mathrm{mm}$ (150-mesh) stainless steel screen.

The individualization of fibers was performed in a
METVISA Type LQ-25 laboratory blender, at a very low consistency. The cellulose pulp was screened for removing the residues from the obtained pulp on a TMP $^{\circledR}$ Máquinas e Sistemas Ltd. laboratory screen, with 0.2-mm slots. After washing, defibration and screening, the brown pulp was dewatered in a centrifuge, to a consistency of approximately $30 \%$ and then stored in polyethylene plastic bags until use.

The brown pulp obtained after the cooking process was divided into three samples, of which one was not modified, the second was subjected to a lignin removal treatment, and the third one was treated for removing hexenuronic acids (Fig. 1).

\section{Treatments}

The treatments for removing lignin and hexenuronic acids were performed according to Ventorim. ${ }^{7}$ The treatment conditions are presented in Tables 2 and 3.

\section{Pre-bleaching}

Pre-bleaching with stages D (chlorine dioxide) and E (alkaline extraction) was performed to obtain a certain amount of AOX in the effluent of these two stages.

Table 1

General conditions used in pulping

\begin{tabular}{lc}
\hline Variable & Conditions \\
\hline Chip mass (g o.d.) & 100 \\
Alkali $\left(\% \mathrm{AA}\right.$ as $\left.\mathrm{Na}_{2} \mathrm{O}\right)$ & 20 \\
Sulfidity $(\%)$ & 30 \\
Liquor:wood ratio (L:kg) & $4: 1$ \\
Time to maximum temperature (min) & 60 \\
Cooking time $(\min )$ & 60 \\
Maximum temperature $\left({ }^{\circ} \mathrm{C}\right)$ & 170 \\
\hline
\end{tabular}

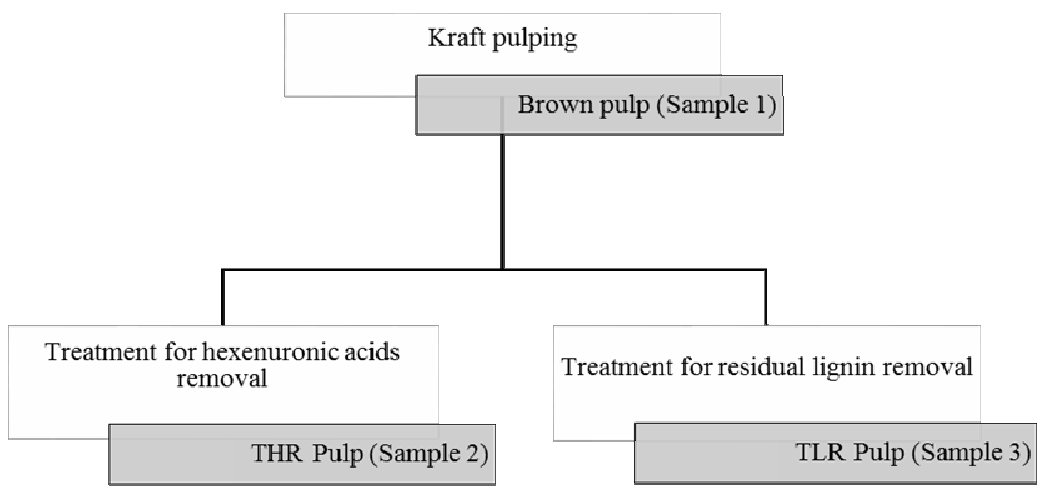

Figure 1: Treatment of pulp samples 
Table 2

General conditions for the removal of lignin

\begin{tabular}{lc}
\hline Variable & Conditions \\
\hline Consistency $(\%)$ & 10 \\
Temperature $\left({ }^{\circ} \mathrm{C}\right)$ & 105 \\
Time $($ min) & 180 \\
$\mathrm{O}_{2}(\mathrm{~kg} / \mathrm{ton})$ & 20 \\
$\mathrm{NaOH}(\mathrm{kg} / \mathrm{ton})$ & 28 \\
$\mathrm{H}_{2} \mathrm{O}_{2}(\mathrm{~kg} / \mathrm{ton})$ & 10 \\
$\mathrm{Cu}(\mathrm{ppm} *)$ & 25 \\
\hline
\end{tabular}

*1 $\mathrm{g}$ of copper per $1 \mathrm{t}$ of cellulosic pulp

Table 3

General conditions for the removal of hexenuronic acids

\begin{tabular}{lc}
\hline Variable & Conditions \\
\hline Consistency $(\%)$ & 10 \\
Temperature $\left({ }^{\circ} \mathrm{C}\right)$ & 110 \\
Time $(\min )$ & 180 \\
$\mathrm{H}_{2} \mathrm{SO}_{4}(\mathrm{~kg} /$ ton $)$ & 15 \\
\hline
\end{tabular}

Table 4

Amount of chlorine dioxide for bleaching at different kappa factors

\begin{tabular}{llccc}
\hline \multicolumn{5}{c}{ Amount of chlorine dioxide (kg/ton) } \\
\hline \multirow{4}{*}{ Kappa } & 0.16 & Brown pulp & THR & TLR \\
factor & 0.18 & 23.8 & 14.7 & 12.0 \\
& 0.20 & 29.8 & 16.5 & 13.5 \\
& 0.22 & 32.8 & 18.4 & 15.0 \\
& 0.24 & 35.8 & 20.2 & 16.5 \\
& & & 22.0 & 18.0 \\
\hline
\end{tabular}

\section{Bleaching with chlorine dioxide}

Equation 1 was used to calculate the amount of chlorine dioxide for kappa factors of $0.16,0.18,0.20$, 0.22 and 0.24 .

Amount of $\mathrm{ClO}_{2}$ as $\mathrm{Cl}_{2}\left(\mathrm{~kg}, \mathrm{t}^{-1}\right)=$ Kappa number $\times$ Kappa factor $\times 10$

The amounts of chlorine dioxide for each bleaching stage performed on the three different samples were calculated and are shown in Table 4.

The bleaching stage with chlorine dioxide was conducted in polyethylene bags on samples of $300 \mathrm{~g}$ of oven dry pulp. Bleaching liquor, which contained $\mathrm{ClO}_{2}, \mathrm{H}_{2} \mathrm{O}$ and $\mathrm{H}_{2} \mathrm{SO}_{4}$, was added to the pulp at room temperature according to these conditions: consistency of $10 \%$, temperature of $60{ }^{\circ} \mathrm{C}$, time of $30 \mathrm{~min}$, and $\mathrm{pH}$ between 2.5 and 3.0.

\section{Alkaline extraction}

Alkaline extraction was performed under the following conditions: consistency of $10 \%$, temperature of $70{ }^{\circ} \mathrm{C}$, duration of $60 \mathrm{~min}$ and $\mathrm{NaOH}$ load of 10 $\mathrm{kg} / \mathrm{t}$.

\section{Methods}

\section{Pulp and effluent analysis}

The methods used in the analysis of the pulps were conducted according to the technical standards of the Technical Association of the Pulp and Paper Industry (TAPPI $){ }^{8}$ Scandinavian Pulp, Paper and Board (SCAN), ${ }^{9}$ and previously published literature according to Table 5 .

\section{RESULTS AND DISCUSSION}

The three pulp samples were characterized by the amount of insoluble lignin, hexenuronic acids and kappa number. The results are shown in Table 6.

\section{AOX in DE stages}

The effluents collected after bleaching with chlorine dioxide and simple extraction were mixed to determine the total amount of AOX in each of the three samples, as a function of the 


\section{TÂNIA CRISTINA FRIGIERI et al.}

different kappa factors used in bleaching with chlorine dioxide (Fig. 2).

Table 5

Methods used in pulp and effluent analyses

\begin{tabular}{lc}
\hline Parameters used & Methodology \\
\hline Sheets production & TAPPI T205 sp-02 (2002) \\
Kappa number & TAPPI T236 om-99 (1999) \\
Hexenuronic acids & Vuorinen et al. $^{10}$ \\
Insoluble lignin & Gomide and Demuner \\
AOX & SCAN-W 9:89 $(2004)$ \\
\hline
\end{tabular}

Table 6

Characterization of pulps (brown, THR, TLR)

\begin{tabular}{lccc}
\hline Parameter & Brown & THR & TLR \\
\hline Insoluble lignin $(\%)$ & 1.56 & 0.83 & 0.32 \\
Hexenuronic acids $(\mathrm{mmol} / \mathrm{kg})$ & 62.9 & - & 57.9 \\
Kappa number & 14.9 & 9.2 & 7.5 \\
\hline
\end{tabular}

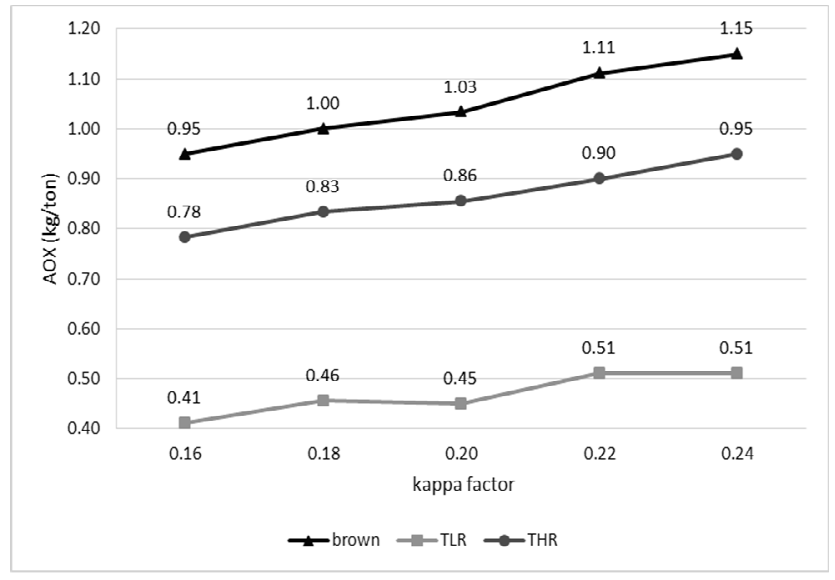

Figure 2: Total AOX of DE stages for different kappa factors

A higher kappa factor resulted in an increase in the amount of chlorine dioxide used in bleaching. Figure 2 shows that, with the increase in the kappa factor, the amount of AOX produced in the effluent was higher, which was similar to the results found by Klein et al., ${ }^{12}$ and PetitBreuilh et al. ${ }^{13}$

It can also be observed that the total value of AOX in the brown pulp effluent was higher when compared to the values of the THR and TLR pulp effluent, which was expected because the brown pulp contained lignin and hexenuronic acids.

The THR pulp, which contained lignin, did not present a great difference when compared to the brown pulp, which indicated that the presence of lignin is the factor that determined a higher amount of AOX. The TLR pulp, which contained hexenuronic acid, presented a much lower value than the other two pulp samples, demonstrating that the hexenuronic acids produced a lower amount of AOX in the effluent when compared to lignin.

The brown pulp produced a higher amount of AOX compared to the THR pulp, because when the removal of hexenuronic acids was performed, a small portion of lignin was also removed, which may have caused the difference in the data observed in Figure 2. Another aspect to consider was that the hexenuronic acids contributed to the formation of AOX.

Because there was an increase in the kappa factor, the increase in the amount of AOX in the three pulp samples was noticeable. This phenomenon was confirmed by Costa and 
Colodette, ${ }^{14}$ and Pimenta, ${ }^{15}$ who stated that sequences with higher chlorine dioxide consumption generate a greater amount of $\mathrm{AOX}$ in the effluent, because there is an increase of $\mathrm{Cl}_{2}$ and/or $\mathrm{HOCl}$ concentration in the system when the amount of chlorine dioxide rises. These are precursors of the chlorinated organic compounds that appear in the effluent (AOX).

The AOX results for the brown pulp with a kappa factor of $0.18(1.0 \mathrm{~kg} / \mathrm{ton})$ matched the data of Barroca et al. ${ }^{16}$ who reported that the sum of the total AOX after the DE sequence was 0.99 $\mathrm{kg} / \mathrm{ton}$. These values reached an average between the limits imposed by environmental regulations, which describe $1.0 \mathrm{~kg}$ AOX/ton of bleached cellulose. Thus, it was verified that this parameter, even before the treatment, was already within the limits recommended by Resolution 430 of May of 2011 of the National Council of the Environment (CONAMA), ${ }^{17}$ which provides environmental guidelines and classification for effluent release.

\section{CONCLUSION}

The amount of AOX found in the effluent after pre-bleaching was higher for brown pulp, because of its higher amount of lignin. The presence of lignin in brown pulp determined an approximately $55 \%$ increase in AOX generation, compared to TLR pulp. Between the THR and TLR pulps, THR pulp was observed to generate a higher amount of AOX. Thus, the amount of AOX generated in THR pulp was approximately $45 \%$ greater than that in TLR pulp. It was concluded that the presence of lignin is the factor that causes a greater amount of $\mathrm{AOX}$, when compared to the effect of the hexenuronic acids.

ACKNOWLEDGEMENTS: The authors would like to thank CAPES (Coordination of Improvement of Higher Level Personnel) for providing financial support for this study.

\section{REFERENCES}

1 R. I. Corazza, Master's Thesis, Campinas State University, Brazil, 1996.

2 A. H. Mounteer in "Cellulose Pulp Bleaching: From Production of Brown Pulp to Finished Product", edited by J. L. Colodette and F. J. B. Gomes, UFV, Viçosa, 2015, pp. 776-780.

3 J. M. V. Pessoa, Master's Thesis, Aveiro University, Portugal, 2007.

4 H. U. Suess, C. Leporini Filho and K. Schmidt, $O$ Papel, 61, 63 (2000).

D. Ruas, Master's Thesis, University of Sao Paulo, Brazil, 2008.

6 J. L. Colodette and V. L. Santos in "Cellulose Pulp Bleaching: From Production of Brown Pulp to Finished Product", edited by J. L. Colodette and F. J. B. Gomes, UFV, Viçosa, 2015, pp. 173-200.

7 G. Ventorim, Ph.D. Dissertation, Federal University of Viçosa, Brazil, 2004.

8 Technical Association of the Pulp and Paper Industry, 2002.

9 SCAN-Scandinavian Pulp, 2004.

10 T. Vuorinen, J. Burchert, A. Teleman, M. Tenkanen and P. Fagerstrom, in Procs. International Pulp Bleaching Conference, Washington, April 14-18, 1996, pp. 43-51.

11 J. L. Gomide and B. J. Demuner, O Papel, 47, 36 (1986).

12 R. J. Klein, W. G. Strunk and A. M. Vegega, in Procs. Pulp and Paper International Non Chlorine Bleaching Conference, San Francisco, March 6-10, 1994, pp. 2-3.

13 X. Petit-Breuilh, R. Melo and C. Zaror, J. Chil. Chem. Soc., 65, 1 (2004), http://dx.doi.org/10.4067/S0717-97072004000400016

14 M.M. Costa and J. L. Colodette, Braz. J. Chem. Eng., 24, 61 (2007), http://dx.doi.org/10.1590/S010466322007000100006.

15 L. M. Pimenta, Master's Thesis, Federal University of Viçosa, Brazil, 2010.

16 M. J. M. C. Barroca, I. M. Seco, P. M. M. Fernandes, L. M. G. A. Ferreira and J. A. A. M. Castro, Environ. Sci. Technol., 35, 4390 (2001), https://doi.org/10.1021/es010019h

17 National Council of the Environment (CONAMA), Conditions and Standards for the Discharge of Effluent (Resolution 430/2011), São Paulo, Brazil, 2011. 